BGPE Discussion Paper

No. 110

\title{
Corporate Insurance with Safety Loadings:
} A Note

\section{Lutz G. Arnold Johannes Hartl}

\section{November 2011}

\section{ISSN 1863-5733}

Editor: Prof. Regina T. Riphahn, Ph.D.

Friedrich-Alexander-University Erlangen-Nuremberg

(c) Lutz G. Arnold, Johannes Hartl 


\title{
Corporate Insurance with Safety Loadings: A Note
}

\author{
Lutz G. Arnold (corresponding author)
} Johannes Hartl

\author{
University of Regensburg \\ Department of Economics \\ 93040 Regensburg, Germany \\ Phone: +49-941-943-2705 \\ Fax: +49-941-943-1971
}

E-mail: lutz.arnold@wiwi.uni-regensburg.de 


\title{
Corporate Insurance with Safety Loadings: A Note
}

\begin{abstract}
In a paper in this journal, Schnabel and Roumi (1989) assert that if uninsured debt is risky, a levered firm takes a casualty insurance with a positive safety loading if, and only if, the amount of debt is sufficiently high. This note shows that, in marked contrast to this assertion, the correct conclusion from their model is that the firm generally takes insurance for low levels of risky debt, and it depends on the magnitude of the loading whether it also takes insurance for high levels of debt.
\end{abstract}

Mayers and Smith (1987) show that corporate insurance resolves the problem that the shareholders of a firm with risky debt $F$ may not benefit from undertaking a positive-NPV investment which mitigates the effects of a casualty loss if the premium is actuarially fair. Elaborating on a remark in Mayers and Smith (1987, p. 50), Schnabel and Roumi (1989) investigate the case of a positive safety loading. They conclude: "there is a critical value of $F$, call it $F^{*} \ldots$ For $F<F^{*}, \ldots$ it is optimal for the firm not to obtain coverage, whereas for $F>F^{*}, \ldots$ it is optimal for the firm to obtain coverage" (Schnabel and Roumi, 1989, p. 157). That is, curiously, the firm takes insurance if, and only if, a sufficiently large portion of the indemnity accrues to the debt holders. In this note, we show that the correct conclusion from their model is in marked contrast to this assertion: the firm generally takes insurance for low levels of risky debt; whether it also takes insurance for high levels of debt depends on the magnitude of the loading.

There are two dates. States of nature at the latter date are indexed by $S \in[0, \bar{S}](\bar{S}>0)$. Payoffs are valued using state prices $g(S) . g(S)$ is positive and atomless for all $S \in[0, \bar{S}]$. Consider a levered firm. At the latter date, in states without a casualty loss, viz., for $S>S_{c}\left(0<S_{c}<\bar{S}\right)$, the firm value is $V^{*}(>0)$. For $S \leq S_{c}$, a casualty loss $L(S)$ occurs at the second date. The firm's assets can be reconstituted at cost $I(S)$, where $0<I(S)<L(S) \leq V^{*}$ for all $0 \leq S<S_{c}$ and $L\left(S_{c}\right)=I\left(S_{c}\right)=0$. That is, repairing the damage is a positive-NPV project. $L(S)$ and $I(S)$ are twice continuously differentiable and strictly decreasing on the interval $\left[0, S_{c}\right]$ (so states with a higher index $S$ are better) with $I^{\prime}(0)>-\infty$. At the first date, the firm generates no cash flow to its shareholders in the absence of insurance. Shareholder value is the sum of the certain cash flows to shareholders at date one (i.e., zero in the absence of insurance) and the value of the residual claim on second-date cash flow, given state prices $g(S)$. The firm repairs the damage if, and only if, this does not reduce shareholder value.

For $F<V^{*}-I(0)$, shareholders have an incentive to reconstitute the firm's assets in each state of nature in which a damage occurs; there is no underinvestment. This is because the ensuing residual claim $V^{*}-I(S)-F$ is positive. Shareholder value is $\int_{0}^{S_{c}}\left[V^{*}-I(S)-F\right] g(S) d S+\int_{S_{c}}^{\bar{S}}\left(V^{*}-F\right) g(S) d S$. As the debt is safe, there is no need to insure it, and the proceeds of the debt issue are $\int_{0}^{\bar{S}} F g(S) d S$. The (first-best) value of the firm (i.e., the sum of shareholder value and the value of the debt) as of the first date is

$$
V_{u}=\int_{0}^{S_{c}}\left[V^{*}-I(S)\right] g(S) d S+\int_{S_{c}}^{\bar{S}} V^{*} g(S) d S .
$$

It is proportional to the area of the pentagon O $\bar{S}$ HJD in Figure 1 (linearity of the curves is assumed for ease of exposition). 
Suppose to the contrary that the firm's debt $F$ to be paid at the second date is large, in that $F \geq V^{*}-I(0)$. Then for any $F$ in the interval $\left[V^{*}-I(0), V^{*}\right]$, there is $S_{a}$ determined by

$$
V^{*}-I\left(S_{a}\right)=F
$$

(see Figure 1). For $S<S_{a}$, the firm value falls short of the face value of debt $F$, even if the firm decides to reconstitute the assets. Ignore corporate insurance to begin with. Then the shareholders prefer not to repair the damage in states $S<S_{a}$, even though this is a positive-NPV project. This is the underinvestment problem identified by Myers (1977, p. 153) and Mayers and Smith (1987, p. 48). ${ }^{1}$ Because of default in states $S<S_{a}$, the debt is risky. Its value as of the first date is

$$
D_{0}=\int_{0}^{S_{a}}\left[V^{*}-L(S)\right] g(S) d S+\int_{S_{a}}^{\bar{S}} F g(S) d S .
$$

Shareholder value is

$$
S_{0}=\int_{S_{a}}^{S_{c}}\left[V^{*}-I(S)-F\right] g(S) d S+\int_{S_{c}}^{\bar{S}}\left(V^{*}-F\right) g(S) d S .
$$

The value of the firm $V_{0}=D_{0}+S_{0}$ is

$$
V_{0}=\int_{0}^{S_{a}}\left[V^{*}-L(S)\right] g(S) d S+\int_{S_{a}}^{S_{c}}\left[V^{*}-I(S)\right] g(S) d S+\int_{S_{c}}^{\bar{S}} V^{*} g(S) d S .
$$

The reduction in the value of the firm compared to the no-underinvestment case $F<V^{*}-I(0)$, i.e., $V_{u}-V_{0}$, is

$$
R_{0}=\int_{0}^{S_{a}}[L(S)-I(S)] g(S) d S
$$

In terms of Figure 1, the value of the risky debt issue $D_{0}$ is proportional to the area of the hexagon $0 \bar{S}$ GCBA, and shareholder value $S_{0}$ is proportional to the area of CGHJ, so $V_{0}$ is proportional to the area of $0 \bar{S}$ HJCBA, and the deadweight loss $R_{0}$ is represented by the sum of the lightly and heavily shaded areas (the tetragon $\mathrm{ABCD})$. In what follows, we focus on risky debt, i.e., on the case $F \geq V^{*}-I(0)$.

Now consider corporate insurance. Following Mayers and Smith (1987, pp. 49-50) and Schnabel and Roumi (1989, p. 156), consider an insurance policy that pays $I(S)-I\left(S_{a}\right)$ conditional on $S \leq S_{a}$. $I\left(S_{a}\right)$ is the maximum deductible that is consistent with providing the firm with an incentive to reconstitute its assets in all states of nature in which a damage occurs: the second-date payoff of the insured firm, if it reconstitutes its assets, becomes $V^{*}-I(S)+\left[I(S)-I\left(S_{a}\right)\right]-F=0$ for $S \leq S_{a}$, so it repairs the damage and the debt is safe. The fair insurance premium is $\int_{0}^{S_{a}}\left[I(S)-I\left(S_{a}\right)\right] g(S) d S$. Following Schnabel and Roumi (1989, p. 157), we assume that the actual insurance premium is

$$
P_{\lambda}=(1+\lambda) \int_{0}^{S_{a}}\left[I(S)-I\left(S_{a}\right)\right] g(S) d S
$$

\footnotetext{
${ }^{1} \mathrm{Hau}(2007)$ shows that overinvestment can occur when asset reconstitution is risky. Consider a state $S$ in which the firm cannot repay its debt without asset reconstitution (i.e., $V^{*}-L(S)<F$ ), and the expected gain to the risky process of asset reconstitution is negative. If, however, $V^{*}-I(S)>F$ for some favorable outcome of the reconstitution process, the firm "gambles for resurrection".
} 


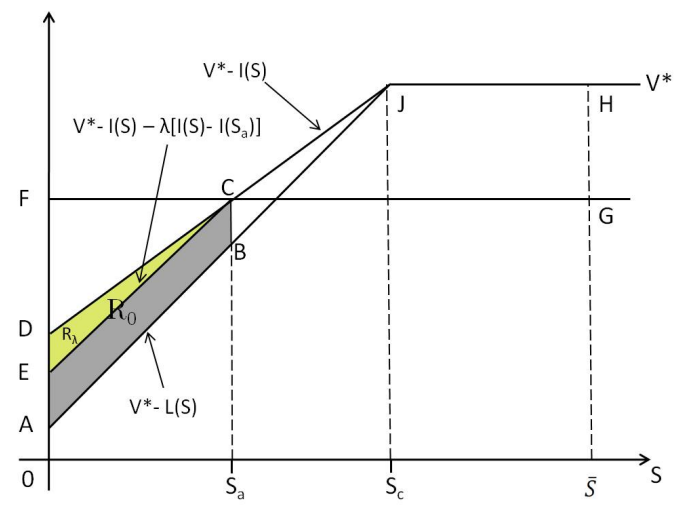

Figure 1: Deadweight losses

where $\lambda(\geq 0)$ is the safety loading. With fair insurance (i.e., if $\lambda=0$ ), decreasing the deductible below $I\left(S_{a}\right)$ and raising the premium accordingly leaves the firm's choice between taking and not taking insurance unaffected (see Mayers and Smith, 1987, p. 51). In the presence of a safety loading (i.e., if $\lambda>0$ ), the use of the maximum deductible consistent with removing the underinvestment problem is efficient, because this minimizes the fair premium and, therefore, also the loading cost. ${ }^{2}$

Following Schnabel and Roumi (1989), we assume that the face value of debt $F$ is the same with or without insurance. Garven and MacMinn (1993, p. 636) call this the "cum dividend interpretation" of the model and point out that it requires careful interpretation, since it implies that the date-one cash flow to shareholders is no longer zero. For one thing, the firm has to pay the insurance premium $P_{\lambda}$ at date one. For another, since insurance makes the debt safe, the value of the debt becomes

$$
D_{\lambda}=\int_{0}^{\bar{S}} F g(S) d S
$$

so the proceeds of the debt issue rise by $D_{\lambda}-D_{0}(\geq 0)$. The firm now pays a dividend $D_{\lambda}-D_{0}-P_{\lambda}$ at the first date. From (1), (2), (5), and (6),

$$
D_{\lambda}-D_{0}-P_{\lambda}=\int_{0}^{S_{a}}[L(S)-I(S)] g(S) d S-\lambda \int_{0}^{S_{a}}\left[I(S)-I\left(S_{a}\right)\right] g(S) d S .
$$

The first integral in the difference on the right-hand side is the deadweight loss without insurance $R_{0}$ (cf. (4)). The second term

$$
R_{\lambda}=\lambda \int_{0}^{S_{a}}\left[I(S)-I\left(S_{a}\right)\right] g(S) d S
$$

is the deadweight loss caused by the safety loading (the fair part of the premium is not a deadweight loss). Let $S_{\lambda}$ denote shareholder value with insurance. The firm takes insurance exactly if $S_{\lambda} \geq S_{0}$. Since the

\footnotetext{
${ }^{2}$ Leaving the confines of the model, there are other reasons for focusing on this insurance policy. If the probability of a casualty loss depends on hidden actions taken by the firm, a high deductible serves to reduce moral hazard. If there is a fixed cost of processing claims, insurance policies which also pay off in higher states cause higher expected cost. A counterargument is that in the worst states (i.e., for $S$ close to zero) the firm is most cash-strained and, therefore, dependent on a low deductible.
} 
shareholders' residual claim at the second date is the same as in the uninsured case (cf. (3)), shareholder value with insurance is $S_{\lambda}=S_{0}+D_{\lambda}-D_{0}-P_{\lambda}=S_{0}+R_{0}-R_{\lambda}$. So $S_{\lambda} \geq S_{0}$ is equivalent to $D_{\lambda}-D_{0}-P_{\lambda} \geq 0$ and to $R_{0} \geq R_{\lambda}$. That is, the firm takes insurance if, and only if, this yields a non-negative dividend at the first date or, equivalently, if the deadweight loss is no greater with insurance than without. In Figure 1, the curve EC depicts $V^{*}-I(S)-\lambda\left[I(S)-I\left(S_{a}\right)\right]$. As in the uninsured case, the value of the shareholders' residual claim on second-date cash flow is represented by CGHJ. The value of the insured debt $D_{\lambda}$ is proportional to the rectangle $0 \bar{S} \mathrm{GF}$; it exceeds the value without insurance by $\mathrm{ABCF}$. This comes at the cost of $P_{\lambda}$, which is the sum of DCF (the fair premium) and the lightly shaded triangle DCE (the loading cost). The fair part of the insurance premium DCF cancels out, so on net the shareholders gain ABCD (i.e., the removal of the deadweight loss $R_{0}$ ) at the expense of DCE (i.e., the deadweight loss $R_{\lambda}$ ).

We have also analyzed the model under the alternative assumption proposed by Garven and MacMinn (1993) that the insured firm adjusts $F$ such that the proceeds of the debt issue are just sufficient to raise what the uninsured debt issue raised and pay the insurance premium, so that the date-one cash flow to shareholders remains zero (see Remark 2 to the theorem below).

The question raised by Schnabel and Roumi (1989) is: how does the level of debt $F$ affect the decision to take insurance or not in the presence of a safety loading? Figure 1 provides a neat graphical intuition. For $F=V^{*}-I(0), \mathrm{ABCD}$ and DCE are both zero, so $R_{0}=R_{\lambda}=0$. When debt $F$ rises marginally, the increase in the deadweight loss without insurance $R_{0}$ is proportional to $\mathrm{BC}$, while the increase in $R_{\lambda}$ is proportional to EC. For $F$ close to $V^{*}-I(0)$, the length of EC is itself close to zero, while the length of BC is not. So the impact of a marginal change in $F$ on $R_{0}$ is an order of magnitude greater than the impact on $R_{\lambda}$ for $F$ close to $V^{*}-I(0)$. As a consequence, the condition for taking insurance $R_{0} \geq R_{\lambda}$ is satisfied for $F$ slightly above $V^{*}-I(0)$. That is, the firm generally takes insurance for low levels of risky debt. Conversely, as $F$ rises towards $V^{*}, \mathrm{BC}$ goes to zero, while EC is bounded away from zero. So for $F$ large enough, $R_{0}-R_{\lambda}$ falls as $F$ rises. Whether or not it becomes negative, so that the firm does not take insurance, depends on the magnitude of the loading $\lambda$.

To put this formally, let $\psi(F)$ be the composite function that relates $R_{0}-R_{\lambda}$ to $F$, where $R_{0}-R_{\lambda}$ is given by the right-hand side of (7) and $S_{a}$ is given by (1). $\psi$ maps $\left[V^{*}-I(0), V^{*}\right]$ on the reals (see Figure 2). It is twice continuously differentiable. The firm takes out insurance if, and only if, $\psi(F) \geq 0$. Let

$$
\bar{\lambda}=\frac{\int_{0}^{S_{c}} L(S) g(S) d S}{\int_{0}^{S_{c}} I(S) g(S) d S}-1
$$

( $>0$ ) denote the value of the loading such that $\psi\left(V^{*}\right)=0$. The firm's decision to ensure is easy to characterize when $\psi$ is strictly concave (the general case is treated in Remark 3 below):

Theorem: Suppose $\psi^{\prime \prime}(F)<0$ for all $F \in\left[V^{*}-I(0), V^{*}\right]$. (a) For $\lambda \leq \bar{\lambda}$, the firm takes out insurance for all $F \in\left[V^{*}-I(0), V^{*}\right]$. (b) For $\lambda>\bar{\lambda}$, there is $F^{*} \in\left(V^{*}-I(0), V^{*}\right)$ such that the firm takes insurance for $F \in\left[V^{*}-I(0), F^{*}\right]$ and does not take insurance for $F \in\left(F^{*}, V^{*}\right]$.

Before proving the theorem, let us relate its implications to Schnabel and Roumi's (1989) assertion quoted in the first paragraph that there is a critical level of debt at which the firm switches from not taking 


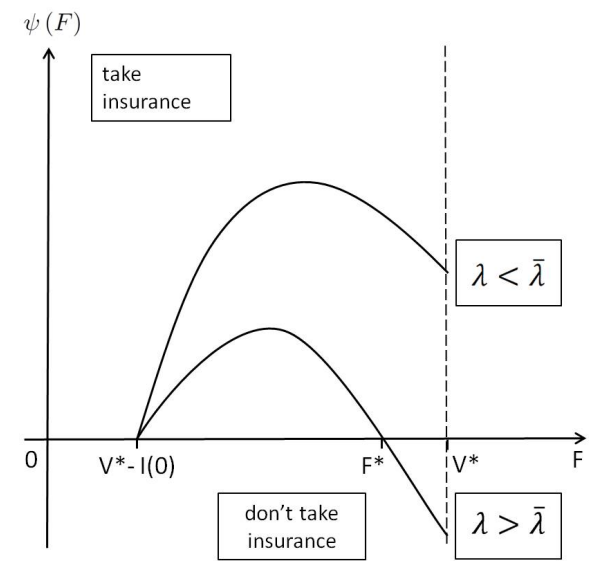

Figure 2: Insurance versus no insurance

insurance to taking insurance. The theorem states, to the contrary, that the firm generally takes insurance for sufficiently low levels of risky debt. According to part (a) of the theorem, for sufficiently low levels of the safety loading, there is no critical value of $F$ at which the firm's insurance decision changes. Part (b) states that for sufficiently high loading, the firm switches from taking to not taking out insurance as $F$ rises above some critical level. From (9), the latter case arises (i.e., $\lambda>\bar{\lambda}$ ) if the loading $\lambda$ and the investment outlays $I(S)$ are large enough relative to the damages $L(S)$. The proof of the theorem essentially elaborates on the graphical argument given above:

Proof: For $F=V^{*}-I(0)$, we have $S_{a}=0$, so from (4) and (8), $R_{0}=R_{\lambda}=0$, i.e., $\psi\left(V^{*}-I(0)\right)=0$. From (1), $d S_{a} / d F=-1 / I^{\prime}\left(S_{a}\right)(>0)$. So from (4) and (8),

$$
\psi^{\prime}(F)=\left[L\left(S_{a}\right)-I\left(S_{a}\right)\right] g\left(S_{a}\right) \frac{-1}{I^{\prime}\left(S_{a}\right)}-\lambda \int_{0}^{S_{a}} g(S) d S,
$$

where $S_{a}$ is given by (1), and in particular

$$
\psi^{\prime}\left(V^{*}-I(0)\right)=[L(0)-I(0)] g(0) \frac{-1}{I^{\prime}(0)}>0 .
$$

From (1), $S_{a}=S_{c}$ for $F=V^{*}$. It follows from (4) and (8) that

$$
\psi\left(V^{*}\right)=\int_{0}^{S_{c}} L(S) g(S) d S-(1+\lambda) \int_{0}^{S_{c}} I(S) g(S) d S .
$$

(a) From the definition of $\bar{\lambda}$ and the fact that $\psi(F)$ falls when $\lambda$ rises, $\psi\left(V^{*}\right) \geq 0$ if $\lambda \leq \bar{\lambda}$. Together with $\psi\left(V^{*}-I(0)\right)=0$ and $\psi^{\prime \prime}(F)<0$, it follows that $\psi(F) \geq 0$, and the firm takes out insurance, for all $F \in\left[V^{*}-I(0), V^{*}\right]$. (b) For $\lambda>\bar{\lambda}$, we have $\psi\left(V^{*}\right)<0$, so there is a unique $F^{*}$ such that $\psi(F) \geq 0$ for $F \in\left[V^{*}-I(0), F^{*}\right]$ and $\psi(F)<0$ for $F \in\left(F^{*}, V^{*}\right]$. This completes the proof of the theorem.

Remark 1: Schnabel and Roumi (1989, fn. 1, p. 157) state mistakenly that

$$
\frac{d R_{\lambda}}{d F}=-\lambda \int_{0}^{S_{a}} \frac{d S_{a}}{d F} g(S) d S<0
$$


They argue that since $d R_{0} / d F>0$ and, allegedly, $d R_{\lambda} / d F<0, R_{0}-R_{\lambda}$ rises as $F$ rises (i.e., insurance becomes relatively more attractive) and conclude that there exists a critical value $F^{*}$ at which the firm switches from not taking to taking out insurance. Actually, $d R_{\lambda} / d F$ is given by the term $\lambda \int_{0}^{S_{a}} g(S) d S(>0)$ in (10). Both $R_{0}$ and $R_{\lambda}$ rise, as $F$ rises, and $R_{0}-R_{\lambda}$ is not monotonic. $R_{0}-R_{\lambda}$ becomes positive at first, but it turns negative for $F$ large if the loading is sufficiently high.

Remark 2: A set of simple conditions which imply that the concavity condition is satisfied is uniformity of $g(S)=g$ on $[0, \bar{S}]$ and linearity of $L(S)=\delta\left(S_{c}-S\right)$ and $I(S)=\gamma\left(S_{c}-S\right)$ (where $\left.0<\gamma<\delta \leq V^{*} / S_{c}\right)$. In this case, (1) and (10) become $S_{a}=S_{c}-\left(V^{*}-F\right) / \gamma$ and

$$
\psi^{\prime}(F)=\frac{g}{\gamma}\left[(\delta-\gamma+\lambda \gamma) \frac{V^{*}-F}{\gamma}-\lambda \gamma S_{c}\right],
$$

respectively. The critical value $\bar{\lambda}$ in (9) is $\bar{\lambda}=\delta / \gamma-1$. It can be shown that in this linear-uniform special case, the assertion of the theorem also holds true under Garven and MacMinn's (1993) alternative assumption that the insured firm adjusts the face value of debt such that the date-one cash flow remains zero, and that the critical value $F^{*}$ is the same as in the cum dividend case. Generally, from (10),

$$
\psi^{\prime \prime}(F)=\frac{1}{I^{\prime}\left(S_{a}\right)}\left\{\frac{d}{d S_{a}}\left[\frac{L\left(S_{a}\right)-I\left(S_{a}\right)}{I^{\prime}\left(S_{a}\right)}\right] g\left(S_{a}\right)+\frac{L\left(S_{a}\right)-I\left(S_{a}\right)}{I^{\prime}\left(S_{a}\right)} g^{\prime}\left(S_{a}\right)+\lambda g\left(S_{a}\right)\right\},
$$

where $S_{a}$ is given by (1). A simple set of sufficient conditions (generalizing the linear-uniform example) for $\psi^{\prime \prime}(F)<0$ is $I^{\prime \prime}(S) \leq 0, L^{\prime}(S)-I^{\prime}(S) \leq 0$, and $g^{\prime}(S) \leq 0$ for all $S \in\left[0, S_{c}\right]$. The first two inequalities imply that the first term in the sum in braces is non-negative, the third inequality ensures that the second term is also non-negative.

Remark 3: The fact that $\psi\left(V^{*}-I(0)\right)=0$ and $\psi^{\prime}\left(V^{*}-I(0)\right)>0$ does not depend on concavity of $\psi$. So the firm generally takes insurance for sufficiently small levels of risky debt. However, when $\psi(F)$ is non-concave, there can be multiple values of $F \in\left(V^{*}-I(0), V^{*}\right)$ at which $\psi(F)=0$ crosses the $F$-axis. In that case, the firm switches back and forth between taking and not taking insurance as $F$ rises. To see that this is a possible outcome of the model, consider the following example. Let $S_{c}=1, V^{*}=1$, $I(S)=0.9004498875-0.9(S+0.001)^{0.5}, L(S)=I(S)+\left(-S^{3}+S^{2}\right)+0.001(1-S)$, and

$$
g(S)=\frac{e^{-0.5\left(\frac{S-0.2}{0.1}\right)^{2}}}{0.1 \sqrt{2 \pi}}
$$

for $S$ in $[0,1]$ (i.e., the distribution of state prices is truncated normal). The example is constructed such that for $S$ small, $L(S)-I(S)$ is small and $I^{\prime}(S)$ is large, so that from $(10), \psi^{\prime}(F)<0$ for $F$ and, hence, $S_{a}$ small enough. (a) For $\lambda=0.05, \psi(F)$ turns negative at $F=0.1769684113$ and positive again at $F=$ 0.3433426436 and terminates at 0.01207642332 for $F=1$. That is, there is an intermediate range of debt levels $(F \in(0.1769684113,0.3433426436))$ for which the firm does not insure. (b) For $\lambda=0.1, \psi(F)$ turns negative at $F=0.1502631825$, becomes positive again at $F=0.4160717224$, finally turns negative at $F=0.8714716708$, and terminates at -0.01256042295 . That is, the firm does not insure at intermediate levels of debt $(F \in(0.1502631825,0.4160717224))$ or with high indebtedness $(F \in(0.8714716708,1])$. 
In sum, we have shown that what keeps a firm from insuring a casualty is the combination of a high safety loading and high indebtedness. Against the background of Mayers and Smith's (1987) analysis of fair insurance, this means in essence that the model outcome is "continuous" in model parameters: a firm generally takes out fair insurance if it can. A firm takes out insurance with a safety loading if the fair premium and/or the loading and, therefore, the deadweight loss of insurance are small enough. For a sufficiently small safety loading, this condition is satisfied for all levels of risky debt. Taking insurance becomes unattractive if, and only if, the loading is sufficiently high and debt is sufficiently large.

\section{References}

Garven, James R., and Richard D. MacMinn (1993), "The Underinvestment Problem, Bond Covenants, and Insurance", Journal of Risk and Insurance 60, 635-46.

Hau, Arthur (2007), "Insurance, Bond Covenants, and Under- or Over-investment With Risky Asset Reconstitution", Journal of Risk and Insurance 74, 3-22.

Mayers, David, and Clifford W. Smith (1987), "Corporate Insurance and the Underinvestment Problem", Journal of Risk and Insurance 54, 45-54.

Myers, Stewart C. (1977), "Determinants of Corporate Borrowing", Journal of Financial Economics 5, $147-75$.

Schnabel, Jacques A., and Ebrahim Roumi (1989), "Corporate Insurance and the Underinvestment Problem: An Extension", Journal of Risk and Insurance 56, 155-9. 